\title{
Zscan4 promotes genomic stability during reprogramming and dramatically improves the quality of iPS cells as demonstrated by tetraploid complementation
}

Jing Jiang ${ }^{1, *}$, Wenjian $\mathrm{Lv}^{1,}{ }^{*}$, Xiaoying Ye ${ }^{2}$, Lingbo Wang ${ }^{1}$, Man Zhang ${ }^{1}$, Hui Yang ${ }^{1}$, Maja Okuka ${ }^{3}$, Chikai Zhou ${ }^{1}$, Xuan Zhang ${ }^{1}$, Lin $\mathrm{Liu}^{2}$, Jinsong $\mathrm{Li}^{1}$

${ }^{I}$ Group of Epigenetic Reprogramming, State Key Laboratory of Cell Biology, Institute of Biochemistry and Cell Biology, Shanghai Institutes for Biological Sciences, Chinese Academy of Sciences, Shanghai 200031, China; ${ }^{2}$ State Key Laboratory of Medicinal Chemical Biology; Department of Cell Biology and Genetics, College of Life Sciences, Nankai University, Tianjin 300071, China; ${ }^{3}$ Department of Obstetrics and Gynecology, University of South Florida College of Medicine, Tampa, FL 33612, USA

Induced pluripotent stem (iPS) cells generated using Yamanaka factors have great potential for use in autologous cell therapy. However, genomic abnormalities exist in human iPS cells, and most mouse iPS cells are not fully pluripotent, as evaluated by the tetraploid complementation assay (TCA); this is most likely associated with the DNA damage response (DDR) occurred in early reprogramming induced by Yamanaka factors. In contrast, nuclear transfer can faithfully reprogram somatic cells into embryonic stem (ES) cells that satisfy the TCA. We thus hypothesized that factors involved in oocyte-induced reprogramming may stabilize the somatic genome during reprogramming, and improve the quality of the resultant iPS cells. To test this hypothesis, we screened for factors that could decrease DDR signals during iPS cell induction. We determined that Zscan4, in combination with the Yamanaka factors, not only remarkably reduced the DDR but also markedly promoted the efficiency of iPS cell generation. The inclusion of Zscan 4 stabilized the genomic DNA, resulting in p53 downregulation. Furthermore, Zscan 4 also enhanced telomere lengthening as early as 3 days post-infection through a telomere recombination-based mechanism. As a result, iPS cells generated with addition of Zscan4 exhibited longer telomeres than classical iPS cells. Strikingly, more than $50 \%$ of iPS cell lines (11/19) produced via this "Zscan4 protocol" gave rise to live-borne all-iPS cell mice as determined by TCA, compared to 1/12 for lines produced using the classical Yamanaka factors. Our findings provide the first demonstration that maintaining genomic stability during reprogramming promotes the generation of high quality iPS cells.

Keywords: somatic reprogramming; genomic stability; telomere; Zscan4; tetraploid complementation; iPS cells Cell Research (2013) 23:92-106. doi:10.1038/cr.2012.157; published online 13 November 2012

\section{Introduction}

The inefficiency of reprogramming [1] and the low quality of induced pluripotent stem (iPS) cells [2] limit their potential applications in cell therapy. While many

*These two authors contributed equally to this work.

Correspondence: Jinsong $\mathrm{Li}^{\mathrm{a}}$, Lin Liu

${ }^{\mathrm{a}}$ Tel: +86215492 1422; Fax: +862154921426

E-mail: jsli@sibcb.ac.cn

${ }^{b}$ E-mail: liutelom@yahoo.com

Received 19 September 2012; Revised 27 September 2012; Accepted 9

October 2012; published online 13 November 2012 studies have described techniques for improving the efficiency of iPS cell generation [3], recent evidence shows that iPS cells harbor aberrant gene expression [4-8] and genomic aberrations [2, 9-13], raising significant concerns about the safety of iPS cells for potential clinical applications. In response to introduction of Yamanaka factors into donor cells, DNA damage response (DDR) is increased and this response is followed by activation of p53 pathway $[14,15]$, which acts as a barrier to reprogramming. The absence or mutation of p53 facilitates nuclear reprogramming; however, p53-deficient or mutant iPS cells present tumor-like features $[16,17]$. Furthermore, most mouse iPS cells fail to give rise to 
live mice as determined by tetraploid complementation assay (TCA), which is the most stringent test for pluripotency $[18,19]$. In contrast, nuclear transfer (NT)-derived embryonic stem (ES) cells (ntES cells), derived from somatic cells by oocyte-mediated rapid reprogramming, are broadly similar to conventional ES cells [20-22] and generate live all-ES cell mice with high efficiency, as determined by TCA [20-22]. Together, these data support the hypothesis that DNA damage and genomic instability arise during reprogramming process induced by the Yamanaka factors, whereas factors involved in oocytemediated reprogramming may play important roles in stabilizing the genome during reprogramming.

Here, we demonstrate that Zscan4, a unique gene highly expressed at the zygotic genome activation stage [23], in combination with the Yamanaka factors, not only dramatically decreases DDR but also significantly promotes iPS cell generation. Zscan4 can stabilize the genomic DNA in the process of somatic reprogramming, probably via rapid enhancement of telomere lengthen- ing, resulting in high quality iPS cells as demonstrated by TCA analyses. Our results indicate that maintaining genomic stability during reprogramming is critical in generation of bona fide iPS cells.

\section{Results}

Zscan4 dramatically decreases DDR during reprogramming and enhances iPS cell generation

We selected 10 factors (Supplementary information, Table S1) that are highly expressed in oocytes or early cleavage-stage embryos and are essential for preimplantation embryonic development. We incorporated each of them individually with the Yamanaka factors to generate iPS cells. We analyzed DDR during iPS cell formation by testing for the presence of phosphorylated histone $\operatorname{H} 2 \mathrm{AX}(\gamma-\mathrm{H} 2 \mathrm{AX}) \cdot \gamma-\mathrm{H} 2 \mathrm{AX}$ is formed rapidly following DNA double-strand breaks (DSBs), which are serious lesions that can cause genomic instability, ultimately leading to cancer [24]. The $\gamma-\mathrm{H} 2 \mathrm{AX}$ assay is frequently used

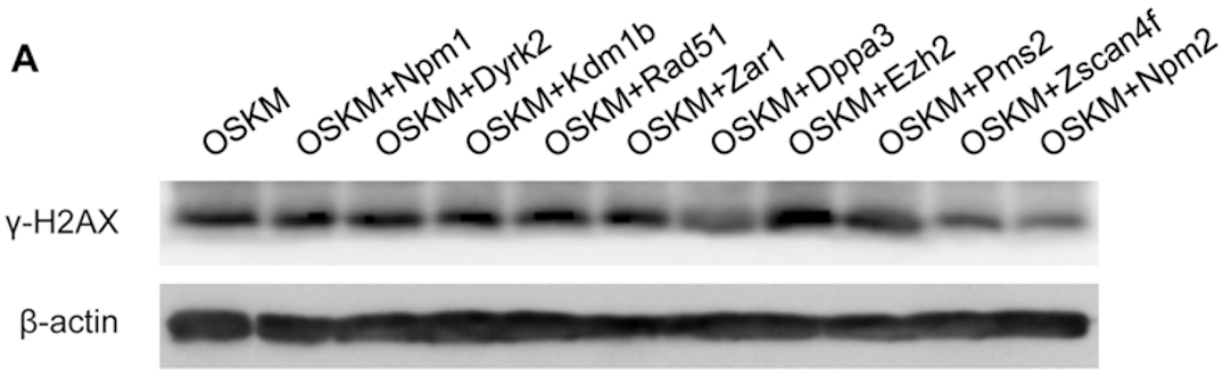

B

\begin{tabular}{|c|c|c|c|c|c|}
\hline Day & Transcription factor & $\begin{array}{l}\text { Oct4-GFP } \\
\text { positive cells\% }\end{array}$ & Day & Transcription factor & $\begin{array}{c}\text { Oct4-GFP } \\
\text { positive cells\% }\end{array}$ \\
\hline \multirow{2}{*}{$12 d$} & OSKM & 0.4 & \multirow{2}{*}{$22 \mathrm{~d}$} & OSK & 0.567 \\
\hline & OSKM+Dppa3 & 0.37 & & OSK+Dppa3 & 1.26 \\
\hline \multirow{2}{*}{$13 d$} & OSKM & 0.375 & \multirow{2}{*}{$20 d$} & OSK & 2.237 \\
\hline & OSKM+NPM2 & 0.35 & & OSK+NPM2 & 2.253 \\
\hline \multirow{2}{*}{$12 \mathrm{~d}$} & OSKM & 0.163 & \multirow{2}{*}{$17 \mathrm{~d}$} & OSK & 0.095 \\
\hline & OSKM+Zscan4f & $2.745 \uparrow$ & & OSK+Zscan $4 f$ & $6.715 \uparrow$ \\
\hline
\end{tabular}

Figure 1 Screening analyses indicate that Zscan4 markedly decreases the DNA damage response and increases reprogramming efficiency. (A) The total phospho-H2AX ( $\gamma-\mathrm{H} 2 \mathrm{AX})$ protein levels were markedly decreased when Zscan4f, Dppa3 and NPM2 were used in combination with the Yamanaka factors. Total protein was extracted from reprogramming cells collected on day 4 after viral transfection. $\beta$-actin was used as a loading control. (B) The reprogramming efficiency was significantly increased when Zscan $4 f$ was used in combination with OSKM or OSK. 
A

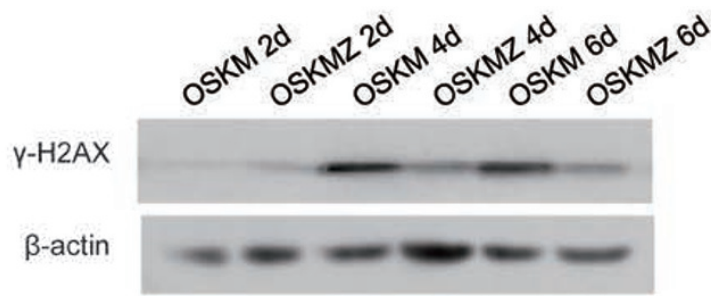

B

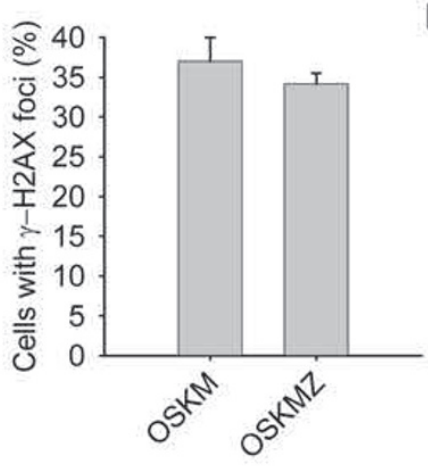

Reprogramming day 7

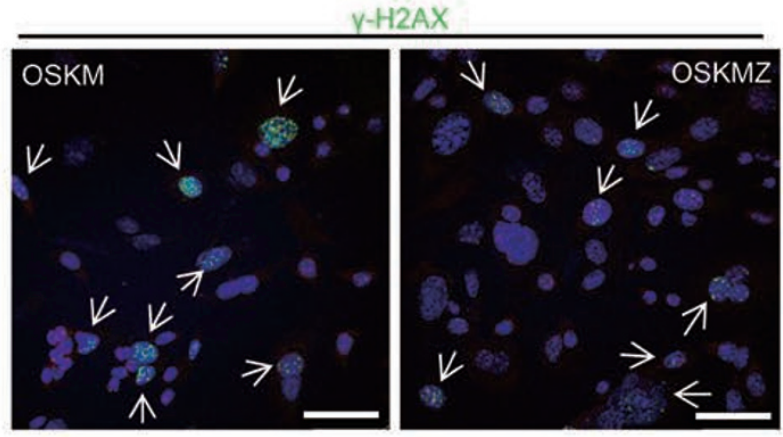

C

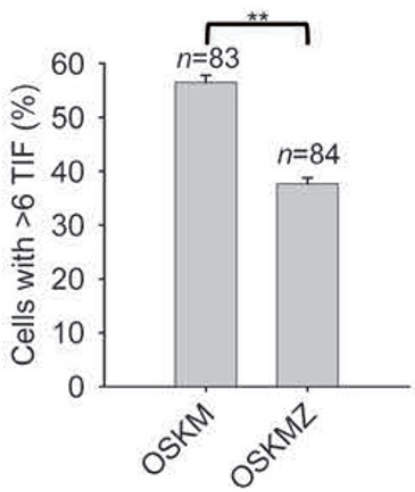

Reprogramming day 7

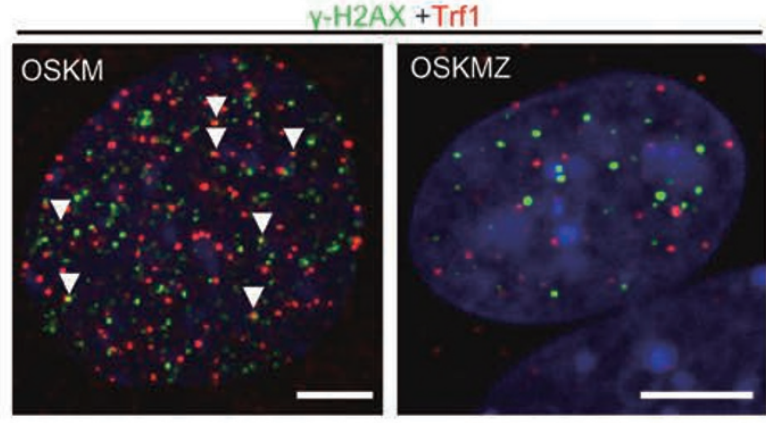

D

\begin{tabular}{cccccc}
\hline $\begin{array}{c}\text { Days after } \\
\text { infection }\end{array}$ & $\begin{array}{c}\text { No. of } \\
\text { cells }\end{array}$ & $\begin{array}{c}\text { No. of } \\
\text { chromosomes }\end{array}$ & $\begin{array}{c}\text { No. of } \\
\text { G-SCEs }\end{array}$ & $\begin{array}{c}\text { No. of G-SCEs } \\
\text { per chromosome (\%) }\end{array}$ & $\begin{array}{c}\text { No. of G-SCEs } \\
\text { per cell }\end{array}$ \\
\hline OSKM 3d & 38 & 1464 & 129 & 8.81 & 3.39 \\
OSKMZ 3d & 43 & 1666 & 74 & 4.44 & 1.72 \\
OSKM 6d & 66 & 2579 & 277 & 10.74 & 4.20 \\
OSKMZ 6d & 69 & 2651 & 166 & 6.26 & 2.41 \\
OSKM 9d & 57 & 2246 & 167 & 7.44 & 2.93 \\
OSKMZ 9d & 55 & 2145 & 117 & 5.45 & 2.13 \\
\hline
\end{tabular}

E
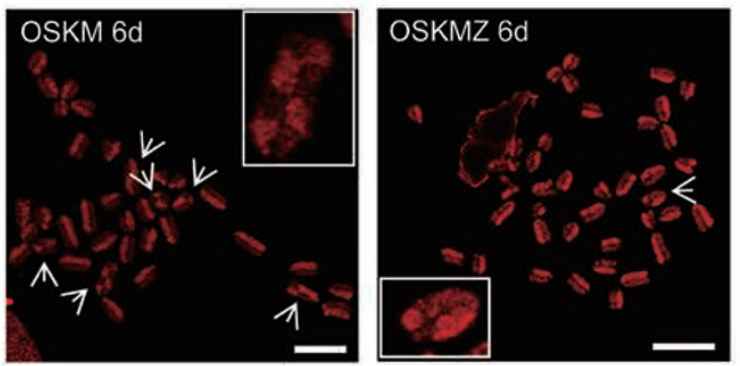

Cell Research | Vol 23 No 1 | January 2013 
for basic studies in DNA damage repair pathways [25] and translational studies of cancer therapies [26]. Therefore, in the initial screening experiments, we examined the total $\gamma-\mathrm{H} 2 \mathrm{AX}$ protein in reprogramming cells collected on day 4 after viral transfection by western blot. We found that three factors, Zscan $4 f, D p p a 3$ and NPM2, in combination with Yamanaka factors, could remarkably decrease the total $\gamma-\mathrm{H} 2 \mathrm{AX}$ protein level at the early stage of reprogramming compared with induction using the classical method (Figure 1A). In the second screening experiments, we tested whether these three factors could also increase efficiency of iPS cell generation by co-introducing one factor with the 'OSK' or 'OSKM' transcription factors into mouse embryonic fibroblasts (MEFs) carrying an enhanced green fluorescence protein (EGFP) reporter driven by Oct4 promoter. Reprogramming efficiency was evaluated by fluorescence-activated cell sorting (FACS) analysis of EGFP-positive cells and Oct4-EGFP-positive colonies in each population on day 12 post-infection. We found that Zscan $4 f$ strongly enhanced reprogramming efficiency in combination with OSK or OSKM (Figure 1B), while the other two factors did not enhance iPS cell formation. This is consistent with a recent independent study, which also showed the enhancement of reprogramming efficiency by Zscan 4 [27].

\section{Zscan4 improves genomic stability during reprogram- ming}

We next carefully evaluated the function of Zscan 4 in iPS cell generation. Zscan4 gene contains a SCAN domain and four zinc finger domains, and three isoforms (Zscan4c, Zscan4d and Zscan4f) encode full-length open reading frames [23]. Zscan4 is expressed specifically in two-cell embryos [23] and transiently in ES cells [28], and plays important roles in preimplantation embryonic development [23] and in the maintenance of genomic stability in ES cells [28]. $\gamma-\mathrm{H} 2 \mathrm{AX}$ was detected in repro- gramming cells two days after MEFs were transduced with either OSKM or OSKM plus Zscan4f (OSKMZ) (Figure 2A). Interestingly, the total $\gamma$-H2AX protein level was reduced in OSKMZ-infected MEFs at days 4 and 6 after reprogramming process was initiated compared to OSKM-infected MEFs (Figure 2A). We next performed immunofluorescence analyses and found that although the percentage of $\gamma-\mathrm{H} 2 \mathrm{AX}$-positive cells among cells undergoing reprogramming did not differ between the two groups $(37.00 \% \pm 2.96 \%$ in OSKM vs $34.19 \% \pm$ $1.34 \%$ in OSKMZ, $P=0.389$ ) (Figure $2 \mathrm{~B}$ ), $\gamma$-H2AXpositive foci were more abundant in OSKM-infected cells than in OSKMZ-infected cells (Figure 2B). Furthermore, colocalization of $\gamma-\mathrm{H} 2 \mathrm{AX}$ and Trf1, indicative of telomere-induced DNA damage foci [28-30], was significantly reduced in OSKMZ-infected cells as compared to OSKM-infected cells (Figure 2C). Because $\gamma$-H2AX is a marker for DSBs [31], we tested general sister chromatid exchange (SCE) $[32,33]$ in reprogramming cells. As expected, the rates of spontaneous SCE in OSKMZinfected MEFs were lower than those in OSKM-infected MEFs during the reprogramming process (Figure 2D and $2 \mathrm{E})$. Together, these data show that overexpression of Zscan4 reduces both DNA damage at telomeres and the incidence of genomic SCE (G-SCE), thus stabilizing the genomes of reprogrammed cells.

Because DDR was reduced during the reprogramming process when Zscan4 was incorporated, we investigated the p53 pathway, which can be activated by DDR, during iPS cell formation induced by Yamanaka factors with or without Zscan $4 f$. As determined by western blot, p53 expression was markedly reduced in OSKMZ-infected MEFs compared to OSKM-infected cells during early stages of reprogramming (Figure 3A). Similarly, expression levels of p21 and bax, two p53 target genes, also decreased (Figure 3A). Inactivation of the p53 pathway markedly enhances the efficiency of iPS cell generation using the standard Yamanaka method $[34,35]$. Consis-

Figure 2 Zscan4 attenuates the DNA damage response and improves genomic stability during reprogramming. (A) Zscan4 reduced DSB signals during reprogramming. Western blot results indicated that the total $\gamma$ - $\mathrm{H} 2 \mathrm{AX}$ level was remarkably reduced during reprogramming. $\beta$-actin was used as a loading control. (B) Left, $\gamma$-H2AX-positive foci in OSKM or OSKMZ virusinfected MEFs on day 7 post-infection. The results shown are the mean of two experiments. More than 600 cells were analyzed per sample/experiment. Error bars, s.d. Right, representative images of $\gamma-\mathrm{H} 2 \mathrm{AX}$-positive foci in OSKM or OSKMZ virusinfected MEFs on day 7 post-infection. White arrows, pan-nuclear $\gamma-\mathrm{H} 2 \mathrm{AX}$. Scale bars, $50 \mu \mathrm{m}$. (C) Left, telomere-induced DNA damage foci in OSKM or OSKMZ virus-infected MEFs on day 7 post-infection. $n=$ number of cells with $\gamma$-H2AX-positive foci analyzed. The results are the mean of two experiments. Error bars, s.d. Right, representative images of $\gamma$-H2AX (green) and Trf1 (red) staining in OSKM or OSKMZ virus-infected MEFs 7 days post-infection. Arrows indicate co-localization events (yellow). Scale bars, $5 \mu \mathrm{m}$. (D) Summary of total G-SCE events in $>35$ nuclei per sample from two independent experiments. (E) Representative images of OSKM (left) or OSKMZ (right) virus-infected MEFs on day 6 post-infection following the G-SCE assay, which demonstrated the reduced rate of SCE observed using the OSKMZ reprogramming system. White arrows mark SCE. The insets are magnified images of one chromosome showing SCE. Scale bars, $10 \mu \mathrm{m}$. 
A

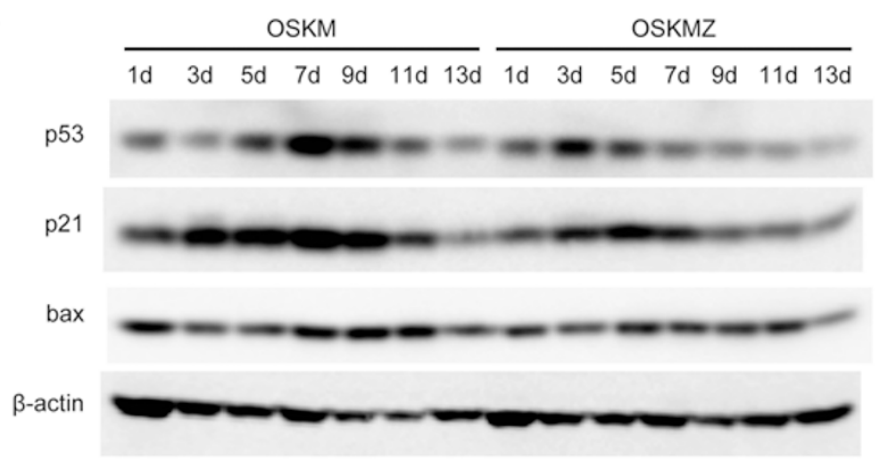

C

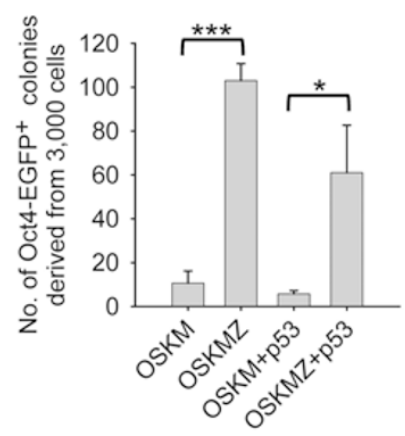

D
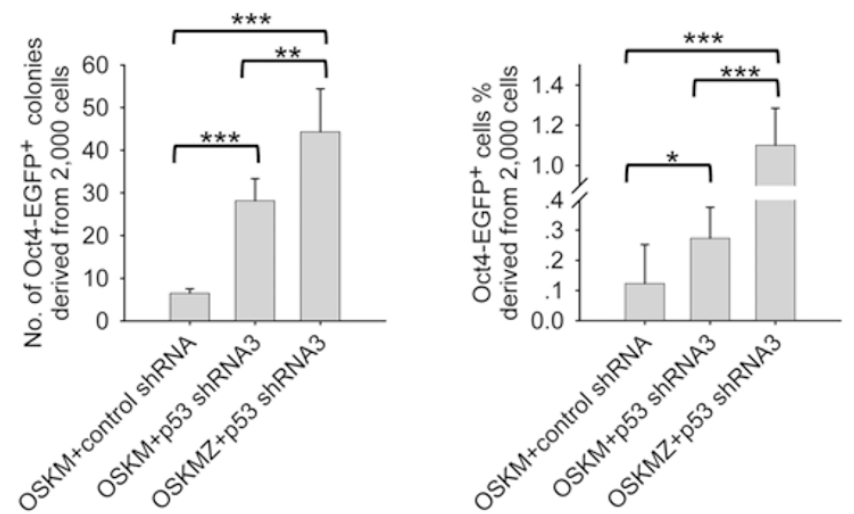
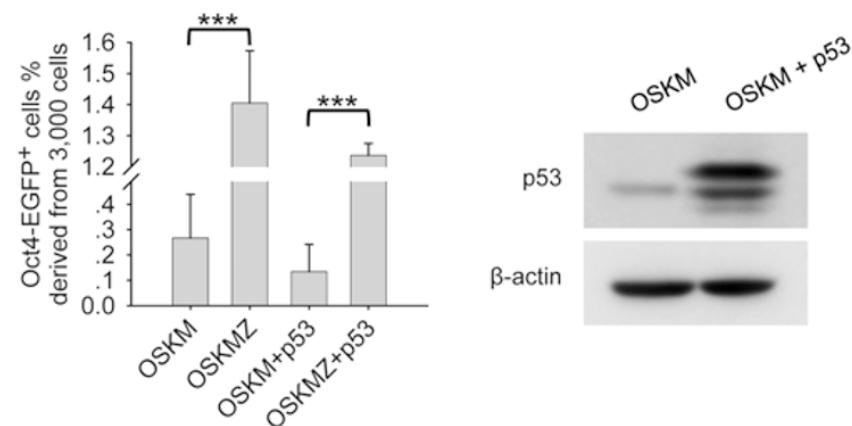

B
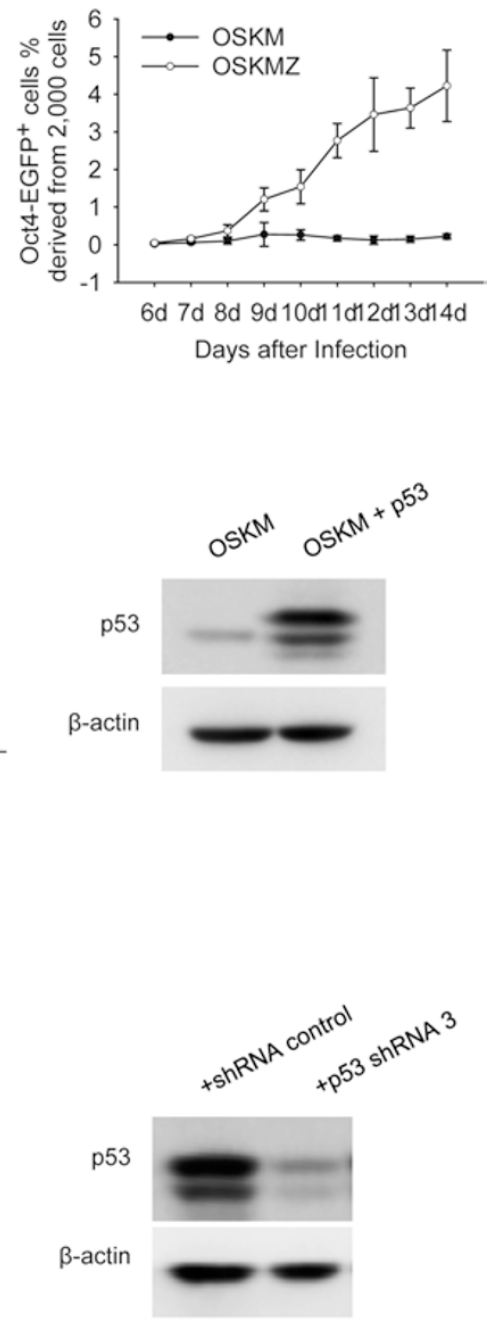

Figure 3 Zscan4 indirectly downregulates p53 during reprogramming. (A) The expression levels of p53, p21 and bax were decreased during reprogramming when Zscan4 was incorporated. Western blot analysis was performed on protein extracts from OSKM- or OSKMZ-infected MEFs at different timepoints. (B) The kinetics of the reprogramming induced by OSKM or OSKMZ virus infection. Oct4-EGFP-positive cells were scored from day 8 to day $14(n=3)$. Error bars, s.d. (C) The overexpression of $p 53$ during reprogramming did not affect the reprogramming efficiency promoted by Zscan4. Quantification of Oct4-EGFP-positive colonies (left) and the percentage of Oct4-GFP-positive cells (middle) are shown $(n=3)$. The expression of $p 53$ was examined by western blot analysis (right). $\beta$-actin was used as a loading control. Error bars, s.d. (D) Knockdown of endogenous $p 53$ by shRNA increased reprogramming efficiency and addition of Zscan4 further promoted the efficiency. Quantification of Oct4-EGFP-positive colonies (left) and the percentage of Oct4-EGFP-positive cells (middle) are shown $(n=3)$. The expression of $p 53$ was examined by western blot analysis (right). $\beta$-actin was used as a loading control. Error bars, s.d.

tent with these results, Zscan $4 f$ significantly facilitated iPS cell formation as assessed by increased Oct4-EGFPpositive cells (Figure 3B and Supplementary information, Figure S1A) and colonies (Supplementary information,
Figure S1B and S1C) on different days post-infection compared to those cells without Zscan $4 f$. In addition, although Oct 4 was typically activated 10 or 14 days after infection with OSKM or OSK, respectively, Oct4 activa- 
tion was observed only 8 days following transfection of OSKMZ or OSKZ (Supplementary information, Figure S1D), suggesting that Zscan $4 f$ accelerated the reprogramming process. We also cloned another analogous gene, Zscan 4c, which is transcribed predominantly in ESCs $[23,36]$, and showed that it has a similar activity during iPS cell generation (Supplementary information, Figure S1E). Furthermore, endogenous Zscan4 was expressed at a low level in MEFs before and after introduction of OSKM or OSKMZ (Supplementary information, Figure S1F). Knockdown of endogenous Zscan 4 by specific small hairpin RNAs (shRNAs) significantly decreased the reprogramming efficiency in comparison with the scrambled control shRNA (Supplementary information, Figure S1G), suggesting that the basal expression level of Zscan 4 is required for generation of mouse iPS cells.

Suppression of $p 53$ increases efficiency of iPS cell generation by classical Yamanaka method; however, this also carries a risk of tumor development due to compromised genome integrity [16, 17]. Therefore, we investigated whether Zscan4 enhances reprogramming efficiency by direct inhibition of the $p 53$ pathway. While the overexpression of $p 53$ reduced reprogramming efficiency of iPS cell generation using OSKM, Zscan4 remarkably increased proportion of Oct4-positive colonies and cells (Figure 3C). Moreover, knockdown of endogenous $p 53$ by shRNA significantly increased reprogramming efficiency, consistent with previous reports [34, 35], and the addition of Zscan4 further increased the proportion of GFP-positive colonies and cells (Figure 3D). Since previous report showed that additional inhibition of the p53 pathway directly accelerated cell division [37], we then tested the effects of Zscan4 on cell cycle during reprogramming. Our results showed that cell growth did not differ between reprogramming cells with and without Zscan4 (data not shown). Taken together, these data indicate that Zscan4-promoted iPS cell generation may not target $p 53$ directly and that downregulation of $p 53$ and its target genes may be concomitant with the improvement of genomic stability.

\section{Zscan4 promotes telomere elongation during reprogram- ming}

Because Zscan4 expression is associated with the maintenance of genomic stability in ES cells, likely by rapid telomere elongation [28], we speculated that $Z s$ can4 induction might contribute to telomere extension during reprogramming. We examined relative telomere length by quantitative telomere FISH (Q-FISH) [38] in OSKM- and OSKMZ-infected MEFs on days 3 and 6 post-infection. Zscan4 promoted telomere elongation starting as early as day 3 following retrovirus infection
(Figure 4A). The rapid telomere lengthening by Zscan4 was not associated with increased telomerase activity because telomerase activity, assessed with the telomeric repeat amplification protocol (TRAP) assay, did not differ between OSKM- and OSKMZ-infected cells (Figure 4B). These results are consistent with a previous report investigating the role of Zscan4 in normal ES cells [28], and suggest that Zscan4 regulates telomere extension during reprogramming, most likely through the same mechanism as in ES cells. Because Zscan4 regulates telomere elongation in ES cells through telomere recombination [28], we then investigated whether Zscan4 activated the telomere sister chromatid exchange (T-SCE) apparatus using a telomere chromosome orientation-FISH (COFISH) assay. As expected, the frequency of T-SCE in OSKM virus-infected MEFs was low and showed no significant difference (average $1.28 \pm 0.21$ per cell) among cells collected from different days post-infection (Figure 4C and 4D). In contrast, addition of Zscan4 resulted in 8.36-fold, 6.20-fold and 4.37-fold increases in T-SCE frequency in OSKMZ-infected MEFs on days 3, 6 and 9 post-infection (Figure 4C and 4D), respectively. We also analyzed expression levels of shelterin components and found that Trf2, Pot1b and Rap1, which can inhibit T-SCE after replication [39, 40], were repressed when Zscan4 was overexpressed (Figure 5A). Other shelterin proteins, Trf1, Pot1a, Tpp1 and Tin2, were not repressed (Figure 5B). These data suggest that Zscan4 expression promotes telomere elongation during iPS cell generation, most likely through telomere recombination involving TSCE.

\section{Zscan4 significantly improves the quality of iPS cells}

Mouse iPS cells generated by OSKM/OSK plus Zscan4 showed ES cell-like morphologies (Supplementary information, Figure S2A). Endogenous Oct4, which serves as a key pluripotency marker, was expressed at levels comparable to those observed in ES cells (Supplementary information, Figure S2B). Meanwhile, endogenous Zscan4, a specific marker for ES cells [28], was activated and expressed at similar levels, while the exogenous expression of retroviral plasmids containing Zscan4 was silenced in the established iPS cell lines (Supplementary information, Figure S2C). OSKMZ- or OSKZ-induced iPS cells formed teratomas comprising all three embryonic germ layers in nude mice (Supplementary information, Figure S2D). To test the in vivo developmental potency of the iPS cells, we injected these cells into diploid blastocysts of ICR origin. Chimeric mice were generated from all tested cell lines (Table 1 and Supplementary information, Figure S2E), and iPS cells contributed to the germline (Supplementary information, Figure S2F). 
A
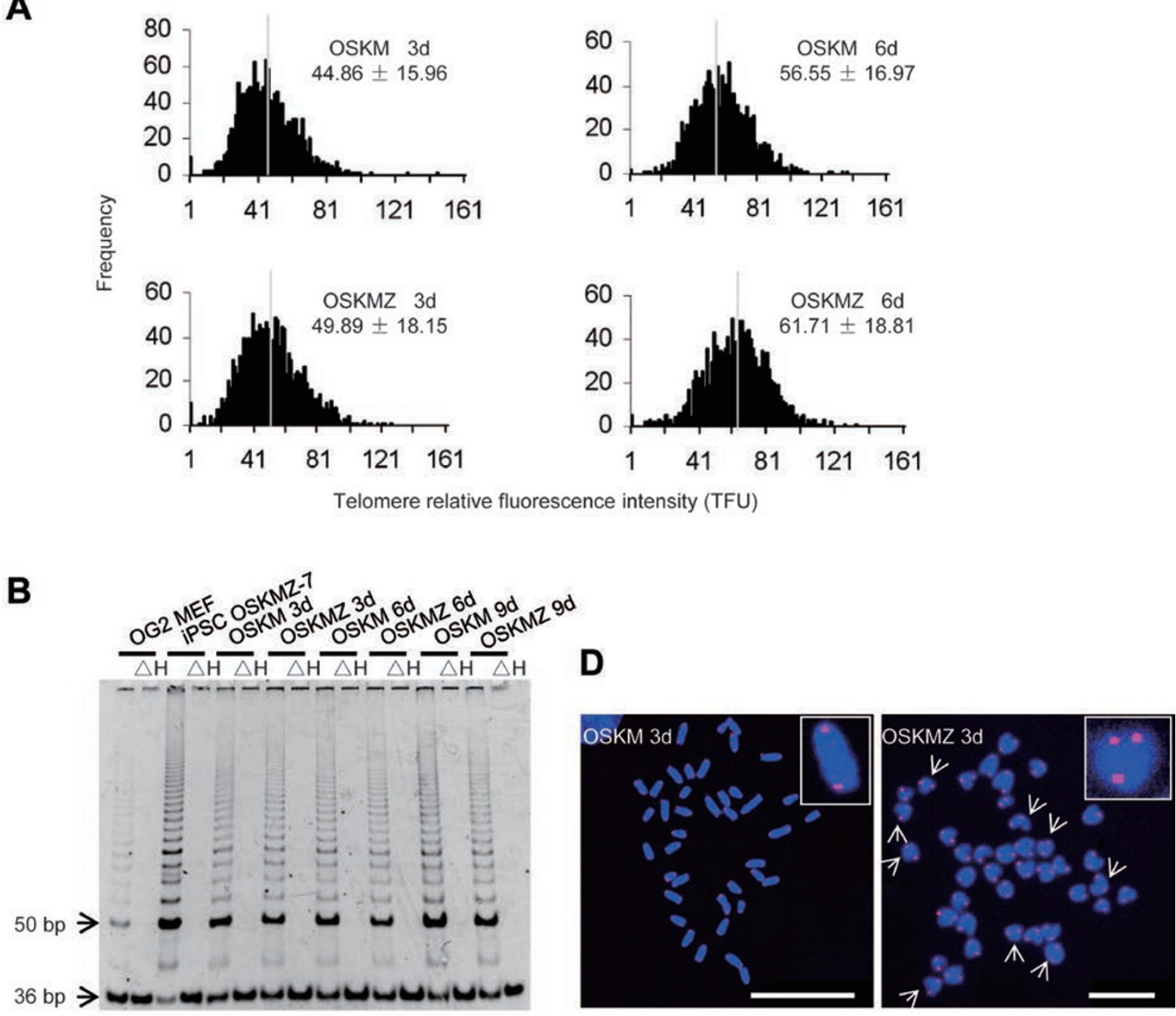

\begin{tabular}{ccccccc}
\cline { 2 - 6 } $\begin{array}{c}\text { Days after } \\
\text { infection }\end{array}$ & $\begin{array}{c}\text { No. of } \\
\text { cells }\end{array}$ & $\begin{array}{c}\text { No. of } \\
\text { chromosomes }\end{array}$ & $\begin{array}{c}\text { No. of } \\
\text { T-SCEs }\end{array}$ & $\begin{array}{c}\text { No. of T-SCEs } \\
\text { per chromosome (\%) }\end{array}$ & $\begin{array}{c}\text { No. of T-SCEs } \\
\text { per cell }\end{array}$ \\
\hline OSKM 3d & 35 & 1368 & 48 & 3.51 & 1.37 \\
OSKMZ 3d & 23 & 884 & 275 & 31.11 & 11.45 \\
OSKM 6d & 26 & 1029 & 27 & 2.62 & 1.04 \\
OSKMZ 6d & 38 & 1473 & 245 & 16.63 & 6.45 \\
OSKM 9d & 27 & 1066 & 39 & 3.66 & 1.44 \\
OSKMZ 9d & 21 & 812 & 132 & 16.26 & 6.29 \\
\hline
\end{tabular}

Figure 4 Zscan4 promotes telomere elongation during reprogramming. (A) A histogram shows the distribution of the relative telomere length (in relative telomere fluorescence units (TFUs)) measured by Q-FISH in OSKM or OSKMZ virus-infected MEFs 3 and 6 days post-infection. The median telomere length (white bars) is shown as the mean \pm s.d. above each panel. (B) Telomerase activity during reprogramming. $\Delta \mathrm{H}$ : heat-inactivation served as a negative control. The $36-\mathrm{bp}$ bands at the bottom of the gel are the internal standard. MEFs (passage 2) and the iPS cell line OSKMZ-7 (passage 10) served as a control. No remarkable differences in telomerase activity between the OSKM- and OSKMZ-infected MEFs were observed during reprogramming. The assays were repeated twice. (C) Summary of total T-SCE events in $>20$ nuclei per sample based on two independent experiments. (D) Representative images of CO-FISH signals in OSKM (left) or OSKMZ (right) virus-infected MEFs on day 3 post-infection: chromosomes were stained with DAPI (blue), and telomeres were marked with a Cy3-conjugated telomere probe (red). White arrows mark T-SCE. The insets are enlarged images of one chromosome showing CO-FISH signals. Scale bars, $25 \mu \mathrm{m}$ (left) and $10 \mu \mathrm{m}$ (right). 
A

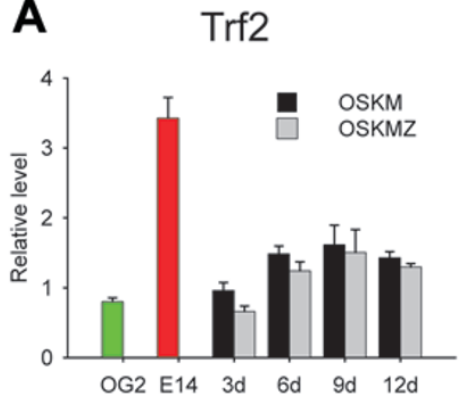

B

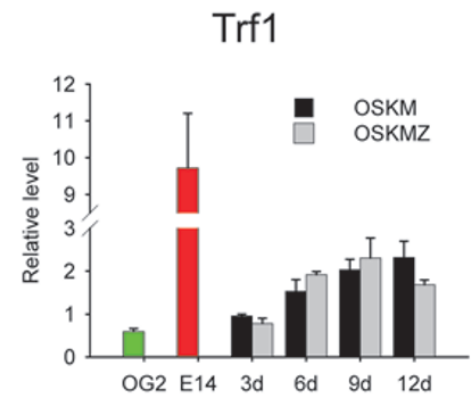

Tpp1

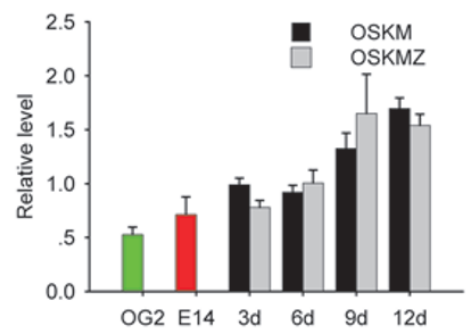

Pot1b

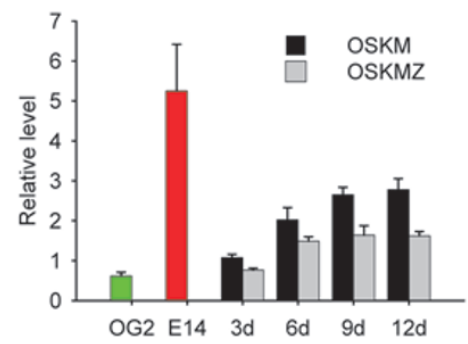

Rap1

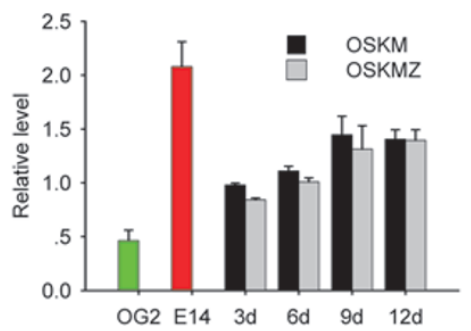

Pot1a

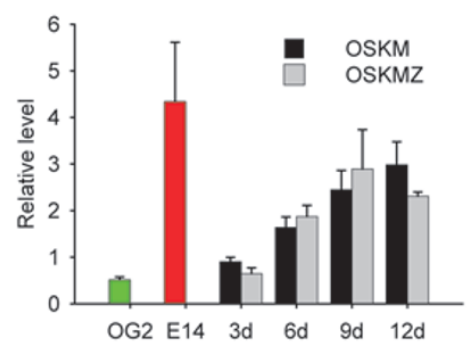

Tin2

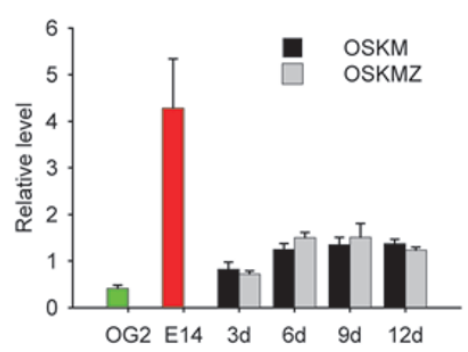

Figure 5 Quantitative RT-PCR for shelterin complex genes during reprogramming. (A) The expression levels of Trf2, Pot1b and Rap1, which inhibit T-SCE after replication, were repressed in OSKMZ-infected MEFs compared to OSKM-infected MEFs during reprogramming. The data are presented as the mean \pm s.d. $(n=3)$. (B) The expression levels of Trf1, Pot1a, Tpp1 and Tin2, the other components of shelterin, were not repressed. The data are presented as the mean \pm s.d. $(n=3)$. The relative expression levels were normalized against the average expression of OSKM virus-infected MEFs on day 3 post-infection.

These data show that the iPS cells generated by OSKMZ or OSKZ are pluripotent.

Overexpression of Zscan4 allowed rapid telomere extension and alleviated DNA damage during reprogramming. We anticipated that the quality of OSKMZ- or OSKZ-induced iPS cells might be improved significantly. We measured telomere length in iPS cells generated with OSKM and OSKMZ using two independent techniques, Southern telomere restriction analysis (TRF) [41] and QFISH on metaphase spreads [38]. As expected, telomeres were longer in OSKMZ-induced iPS cells compared to the corresponding OSKM-induced iPS cells, as determined by both TRF (Figure 6A) and Q-FISH analysis (Figure 6B), indicating that Zscan4 contributes to the generation of iPS cells with longer telomeres. We next tested the in vivo developmental potential of OSKMZ iPS cells by TCA, which is the most stringent assay for pluripotency and also the most reliable functional assay to determine the quality and genomic stability of mouse iPS/ES cells [42]. Remarkably, 5 out of the 8 OSKMZinduced iPS cell lines gave rise to viable all-iPS cellderived pups at an efficiency similar to that of ES cells and ntES cells, as described in previous reports [42, 43] (Figure 6C and 6D and Table 1). In contrast, all 5 OSKM-induced iPS cells with the same genetic background failed to produce iPS cell-derived pups. Likewise, in 6 OSK-induced iPS cells, only 1 cell line generated one live-born pup, whereas 6 out of 11 OSKZ iPS cell lines produced live-born all-iPS cell-derived pups (Figure 6C and $6 \mathrm{D}$ and Table 1). Genotyping analysis showed that 
all-iPS cell mice carried the Zscan4 and Oct4 transgenes (Figure 6E, left). We further verified the cell origin of these mice by simple sequence-length polymorphism (SSLP) analysis and confirmed that they were from iPS cells with an inbred genetic background (C57BL/6 strain) and not the tetraploid embryo host or recipient ICR mice (Figure 6E, right). Interestingly, ES cells derived from an inbred background, such as the C57BL/6 mouse strain,

Table 1 In vivo-developmental potency of iPS cells

\begin{tabular}{|c|c|c|c|c|c|c|}
\hline \multirow[t]{2}{*}{ Donor Cells } & \multirow[t]{2}{*}{ Factors } & \multicolumn{3}{|c|}{$2 \mathrm{~N}$ injections } & \multicolumn{2}{|c|}{ 4N injections } \\
\hline & & Blastocysts injected & Chimeric/Total & Chimaerism $(\%)^{a}$ & Blastocysts injected & Live pups (\%) \\
\hline OSKM-1 & $\mathrm{O}, \mathrm{S}, \mathrm{K}, \mathrm{M}$ & 14 & $4 / 6$ & $20-80$ & 136 & 0 \\
\hline OSKM-2 & $\mathrm{O}, \mathrm{S}, \mathrm{K}, \mathrm{M}$ & ND & ND & ND & 113 & 0 \\
\hline OSKM-3 & $\mathrm{O}, \mathrm{S}, \mathrm{K}, \mathrm{M}$ & 22 & $4 / 7$ & $40-70$ & 125 & 0 \\
\hline OSKM-4 & $\mathrm{O}, \mathrm{S}, \mathrm{K}, \mathrm{M}$ & ND & ND & ND & 153 & 0 \\
\hline OSKM-5 & $\mathrm{O}, \mathrm{S}, \mathrm{K}, \mathrm{M}$ & 16 & $1 / 2$ & 70 & 139 & 0 \\
\hline Subtotal & & & & & 666 & 0 \\
\hline OSKMZ-1 & $\mathrm{O}, \mathrm{S}, \mathrm{K}, \mathrm{M}, \mathrm{Z}$ & 40 & $2 / 6$ & 30,90 & 194 & $5(2.58)^{b}$ \\
\hline OSKMZ-2 & $\mathrm{O}, \mathrm{S}, \mathrm{K}, \mathrm{M}, \mathrm{Z}$ & 28 & $1 / 3$ & 5 & 192 & $3(1.56)^{b}$ \\
\hline OSKMZ-3 & $\mathrm{O}, \mathrm{S}, \mathrm{K}, \mathrm{M}, \mathrm{Z}$ & 16 & $2 / 3$ & 10,60 & 83 & $1(1.20)^{b}$ \\
\hline OSKMZ-5 & $\mathrm{O}, \mathrm{S}, \mathrm{K}, \mathrm{M}, \mathrm{Z}$ & ND & ND & ND & 109 & $0^{\mathrm{b}}$ \\
\hline OSKMZ-6 & $\mathrm{O}, \mathrm{S}, \mathrm{K}, \mathrm{M}, \mathrm{Z}$ & ND & ND & ND & 80 & $1(1.25)^{b}$ \\
\hline OSKMZ-7 & $\mathrm{O}, \mathrm{S}, \mathrm{K}, \mathrm{M}, \mathrm{Z}$ & 16 & $2 / 2$ & 50,80 & 120 & $2(1.67)^{b}$ \\
\hline OSKMZ-8 & $\mathrm{O}, \mathrm{S}, \mathrm{K}, \mathrm{M}, \mathrm{Z}$ & ND & ND & ND & 117 & 0 \\
\hline OSKMZ-9 & $\mathrm{O}, \mathrm{S}, \mathrm{K}, \mathrm{M}, \mathrm{Z}$ & ND & ND & ND & 121 & 0 \\
\hline Subtotal & & & & & 1016 & $12(1.18)$ \\
\hline OSK line1.1 & $\mathrm{O}, \mathrm{S}, \mathrm{K}$ & ND & ND & ND & 137 & 0 \\
\hline OSK line1.4 & $\mathrm{O}, \mathrm{S}, \mathrm{K}$ & 15 & $4 / 7$ & 70,80 & 162 & 0 \\
\hline OSK line2.4 & $\mathrm{O}, \mathrm{S}, \mathrm{K}$ & 17 & $2 / 2$ & 70,90 & 166 & $0^{\mathrm{b}}$ \\
\hline OSK line23 & $\mathrm{O}, \mathrm{S}, \mathrm{K}$ & 14 & $1 / 3$ & 90 & 105 & $1(0.95)$ \\
\hline OSK-1 & $\mathrm{O}, \mathrm{S}, \mathrm{K}$ & ND & ND & ND & 115 & 0 \\
\hline OSK-2 & $\mathrm{O}, \mathrm{S}, \mathrm{K}$ & ND & ND & ND & 155 & 0 \\
\hline OSK-3 & $\mathrm{O}, \mathrm{S}, \mathrm{K}$ & ND & ND & ND & 141 & 0 \\
\hline Subtotal & & & & & 981 & $1(0.10)$ \\
\hline OSKZ-1 & $\mathrm{O}, \mathrm{S}, \mathrm{K}, \mathrm{Z}$ & 15 & $2 / 10$ & 20,20 & 30 & $1(3,33)$ \\
\hline OSKZ-10 & $\mathrm{O}, \mathrm{S}, \mathrm{K}, \mathrm{Z}$ & 15 & $1 / 6$ & 30 & 148 & $2(1.35)^{b}$ \\
\hline OSKZ-12 & $\mathrm{O}, \mathrm{S}, \mathrm{K}, \mathrm{Z}$ & 18 & $1 / 6$ & 70 & 104 & 0 \\
\hline OSKZ-14 & $\mathrm{O}, \mathrm{S}, \mathrm{K}, \mathrm{Z}$ & 26 & $1 / 3$ & 80 & 115 & $0^{\mathrm{b}}$ \\
\hline OSKZ-16 & $\mathrm{O}, \mathrm{S}, \mathrm{K}, \mathrm{Z}$ & ND & ND & ND & 143 & $0^{\mathrm{b}}$ \\
\hline OSKZ line8 & $\mathrm{O}, \mathrm{S}, \mathrm{K}, \mathrm{Z}$ & 18 & $1 / 3$ & 30 & 87 & $0^{\mathrm{b}}$ \\
\hline OSKZ line 16 & $\mathrm{O}, \mathrm{S}, \mathrm{K}, \mathrm{Z}$ & ND & ND & ND & 91 & $0^{\mathrm{b}}$ \\
\hline OSKZ line 18 & $\mathrm{O}, \mathrm{S}, \mathrm{K}, \mathrm{Z}$ & ND & ND & ND & 48 & $1(2.08)$ \\
\hline OSKZ line22 & $\mathrm{O}, \mathrm{S}, \mathrm{K}, \mathrm{Z}$ & ND & ND & ND & 73 & 0 \\
\hline OSKZ line24 & $\mathrm{O}, \mathrm{S}, \mathrm{K}, \mathrm{Z}$ & 16 & $2 / 4$ & 10,50 & 35 & $1(2.86)$ \\
\hline OSKZc-1 & $\mathrm{O}, \mathrm{S}, \mathrm{K}, \mathrm{Z}$ & ND & ND & ND & 40 & $2(5)$ \\
\hline Subtotal & & & & & 914 & $7(0.77)$ \\
\hline
\end{tabular}

Z, Zscan4f; Zc, Zscan4c; O, Oct4; S, Sox 2; K, Klf4; M, c-Myc;

a, the extent of chimaerism was estimated on the basis of coat colour;

b, embryonic lethal at E10-19;

ND, not determined. 
A

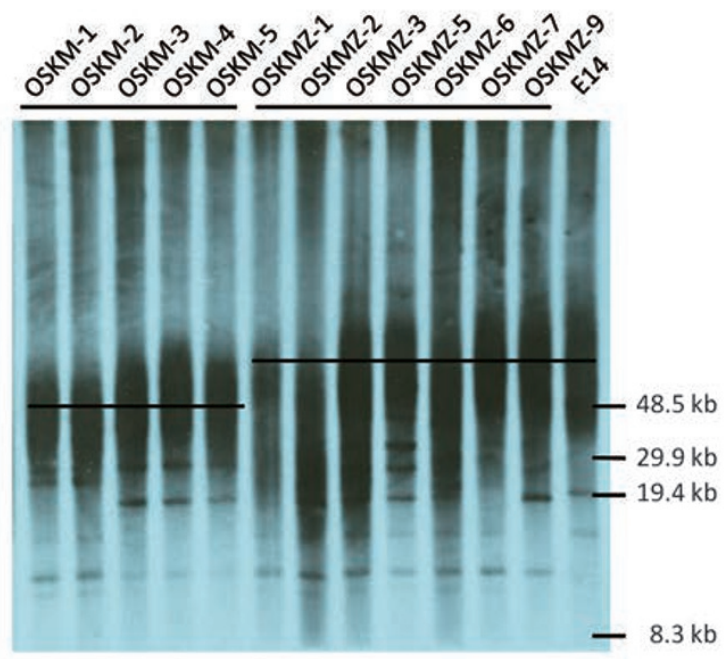

C

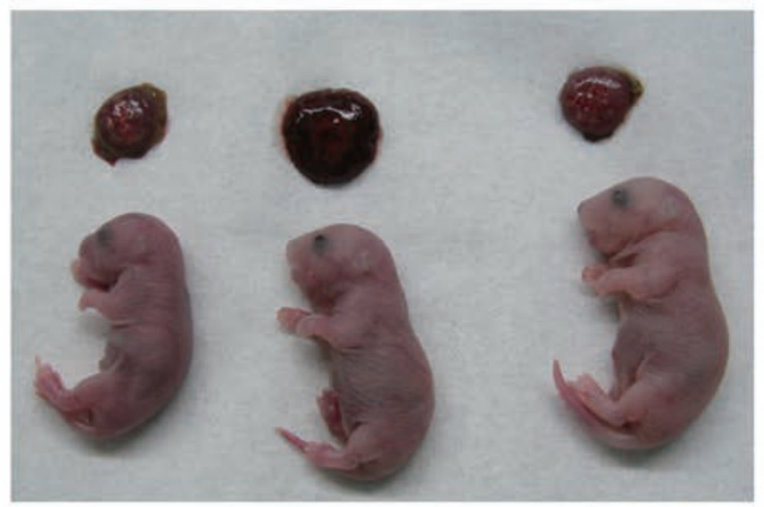

B
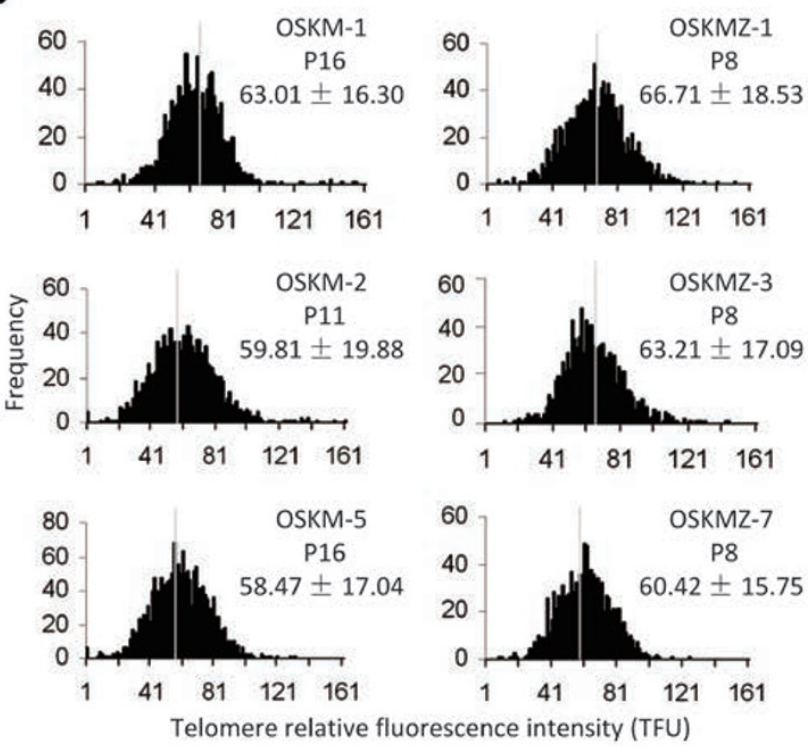

D
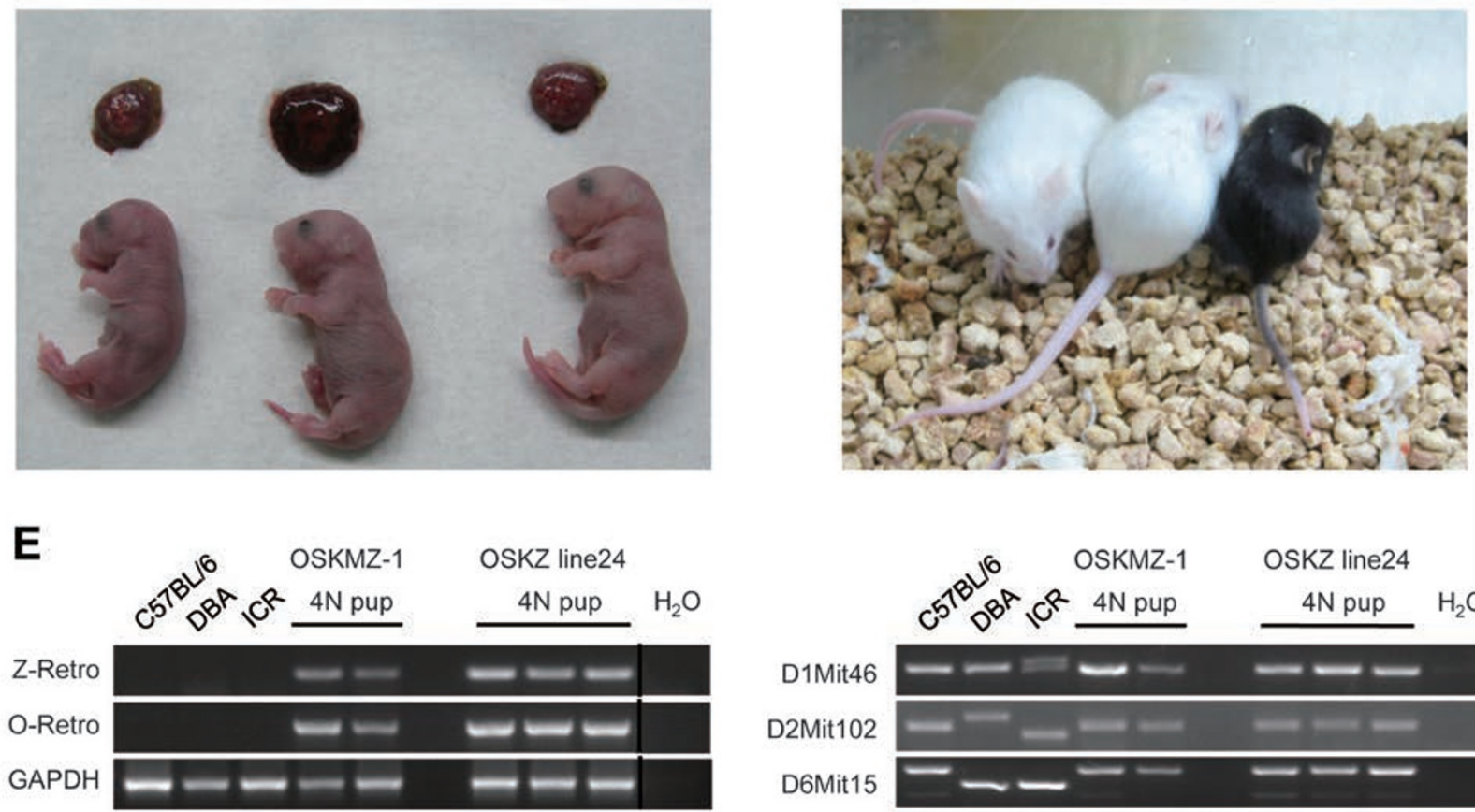

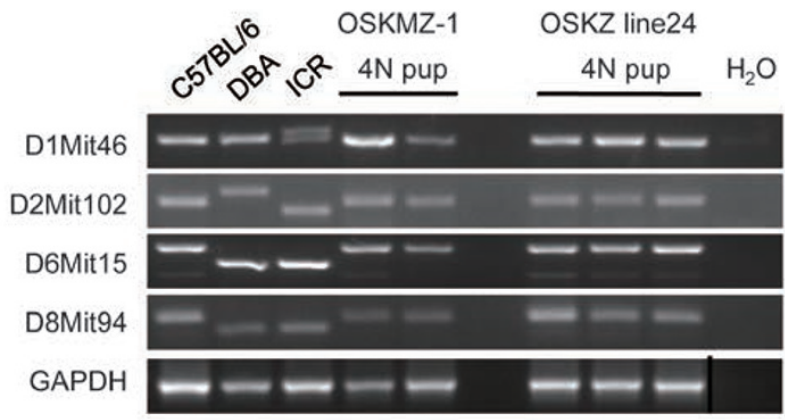

Figure 6 Zscan4 leads to longer telomeres in the resultant iPS cells and significantly improves the developmental potential of iPS cells. (A) TRF analysis of iPS cells and control ES cells (E14) between passages 7-10 demonstrated longer telomeres in OSKMZ-induced iPS cells compared to OSKM-induced iPS cells. (B) A histogram shows the distribution of relative telomere length (in TFUs) measured by Q-FISH in iPS cells. The median telomere length (white bars) is shown as the mean \pm s.d. above each panel. The passage number was indicated. (C) Three live-born (E19.5) all-iPS cell mice generated from OSKMZ-1 cells via TCA. (D) An adult all-iPS cell mouse generated from OSKMZ-1 via TCA. (E) Genotype analyses of all-iPS cell mice. Retrovirus integration (left) and SSLP (right) analyses were performed using genomic DNA isolated from tail tips of adult mice. Genomic DNA from C57BL/6, DBA and ICR mice served as controls. 
were less able to generate cloned and all-ES cell pups [44]. These data demonstrate that the iPS cells generated by the addition of Zscan4 exhibit high quality and show improved developmental potential in vivo in contrast to iPS cells derived using classical OSK or OSKM technique.

\section{Discussion}

The conversion of somatic cells to iPS cells by Yamanaka factors remains an inefficient process [1, 45]. Although significant progress has been made in terms of improving the efficiency of iPS cell generation through the use of chemical compounds [46, 47] and different cell types [48, 49], interfering with the epigenetic status of donor cells [50-52], or modulating different signal pathways $[34,53,54]$, the quality of iPS cells to date is not significantly improved or even getting worse when the $p 53$ was absent to facilitate reprogramming [35]. On the other hand, regarding the safety concerns of iPS cells, strategies of generating integration-free iPS cells have been developed [55]; however, these reprogramming processes are extremely inefficient and the quality of resulting integration-free iPS cells still needs to be completely characterized [56]. In our study, we identified Zscan4 as a factor, essential for cleavage development of mouse embryos [23], which not only remarkably promotes the efficiency of iPS cell generation, but also significantly improves the quality of iPS cells by stabilizing the genomic and telomere DNA and promoting the telomere elongation at early stage of reprogramming. Consistently, a recent independent study [27] also verified that Zscan4 can improve the reprogramming efficiency.

Recently, several studies reported that genetic abnormalities are found in human iPS cells derived from fibroblasts [2, 9-11, 13], implying the importance of maintaining genomic integrity during cellular reprogramming. During the first several cell cycles following fertilization, when epigenetic reprogramming occurs, the telomeres of the parental chromosomes lengthen remarkably, and 1- to 2-cell stage embryos have elongated telomeres [57], while the telomeres in mature oocytes are shorter than those in somatic cells [57]. Also, telomeres become shorter during the pachytene spermatocyte stage until round spermaid [58]. This extension could be related to T-SCE [57], which may be regulated by Zscan4; Zscan4 is highly expressed in late 2-cell embryos [23] and can promote rapid telomere elongation in ES cells via T-SCE [28]. Taken together, these observations suggest that rapid telomere elongation following fertilization may protect DNA from damage induced by acute epigenetic reprogramming. These findings may also partially explain why NT can faithfully reprogram so- matic cells into ES cells [5, 8, 20, 21, 42]. In contrast, during somatic reprogramming induced by the Yamanaka factors, telomere elongation is primarily mediated by telomerase [59, 60]. Endogenous Zscan4 is not activated during the early stages of reprogramming induced by OKSM or OSK, as shown in our study (Supplementary information, Figure S1F) and in other report [38], further supporting the hypothesis that telomerase activity is the primary mechanism of telomere re-elongation regulation during OSKM- or OSK-mediated reprogramming. However, telomere extension by telomerase is a slow process and requires a number of cell divisions to restore a normal average telomere length $[59,61]$. The delay in telomere extension by telomerase alone may not properly protect the genome, especially during the early stages of reprogramming when most epigenetic reprogramming events occur. As a result, most reported iPS cell lines are unable to generate live-born mice through TCA $[18,19$, 42]. Here, we report that overexpression of Zscan4 promotes rapid telomere extension by facilitating T-SCE at early stages of iPS cell formation, resulting in not only significant improvement of reprogramming efficiency but also significant improvement of iPS cell quality. Our study provides the first evidence that factors involved in the process of ooctye-mediated reprogramming can help maintain genomic stability during reprogramming and thus promote generation of high quality iPS cells.

\section{Materials and Methods}

\section{Cell culture}

iPS cells and ES cells were cultured on irradiated feeder cells in mouse ES cell medium containing leukemia inhibitory factor (LIF), $15 \%$ FBS (Gibco), nonessential amino acids, L-glutamine, nucleosides, 2-mercaptoethanol and penicillin/streptomycin. iPS cells and ES cells were passaged every 2-3 days. MEFs, plat-E packaging cells and feeder cells were cultured in MEF medium containing $10 \%$ FBS, nonessential amino acids and penicillin/streptomycin. Feeder cells were generated by irradiating ICR MEFs. MEFs were derived from E13.5 embryos of C57BL/6 mice that were heterozygous for the Oct4-GFP transgenic allele, as previously described $[60,62]$. In this study, we used MEFs within the first three passages for iPS cell generation to avoid replicative senescence.

\section{Generation of iPS cells}

Mouse iPS cells were generated with retroviruses as previously described [62]. Retrovirus was produced by transfecting plat-E cells with pMXs retroviral vectors. MEFs from OG2 mice, which carry a transgenic Oct 4 promoter driving GFP expression, were seeded at a density of $8 \times 10^{4}$ cells per well in six-well plates $12 \mathrm{~h}$ before infection. Virus-containing supernatants from the plat-E cultures were recovered and combined (e.g., to mix viruses for Oct4, Sox2, Klf4, c-myc and Zscan4). Virus-containing supernatants supplemented with $4 \mu \mathrm{g} / \mathrm{ml}$ polybrene were added to the plates of MEFs, and this day was defined as "Day 0". The culture 
medium was changed $12 \mathrm{~h}$ later. Four days post-infection, MEFs were digested into single cells and reseeded at a density of 2000 cells (OSKM/OSKMZ), $2 \times 10^{4}$ cells (OSK/OSKZ) per well in six-well plate, or 3000 cells (OSKM/OSKMZ + p53) per well in six-well plates pre-seeded with irradiated feeder cells. The culture medium was changed into mouse ES cell medium at day 5 postinfection and was changed daily.

To quantify the reprogramming efficiency using the Oct4-GFP reporter, GFP-positive colonies were counted using an Olympus inverted fluorescent microscope. Colonies were also trypsinized and analyzed using Becton Dickinson FACS Calibur cell sorter. GFP-positive cells were gated with a control signal from the PE channel, and a minimum of 30000 events were recorded. Numbers of GFP-positive colonies and the percentage of GFP-positive cells were scored at day 12 for OSKM/OSKMZ and day 16 for OSK/ OSKZ.

\section{Plasmid construction}

Full-length cDNAs of murine Zscan $4 f, N p m 1$ and the other genes shown in Supplementary information, Table S1 were cloned into the retroviral vector pMXs. The short hairpin RNAs (shRNAs) that targeted mouse Zscan 4 mRNA, p53 mRNA and the control shRNA were cloned into the pMKO.1 retroviral vector, which was obtained from Addgene (Addgene, Cambridge, MA, http:// www.addgene.org). The Zscan4 shRNA target sequences were: GACCTTCAGACCAACAATTTA (Z shRNA1) and GAAATGGACTCCCTTCTTATT (Z shRNA2). The $p 53$ shRNA target sequence was: GTACATGTGTAATAGCTCCTG (p53 shRNA3). A randomly distributed sequence was used as a control: GATTAATAGGATTGCAGAATT.

\section{Quantitative PCR}

Total RNA was isolated from the cells using TRIzol reagent (Invitrogen). One microgram of total RNA was reverse transcribed using an iScript ${ }^{\mathrm{TM}}$ cDNA Synthesis kit (Bio-Rad). Real-time quantitative PCR reactions were set up in triplicate using $\mathrm{iQ}^{\mathrm{TM}} \mathrm{SYBR}$ Green Supermix (Bio-Rad) and run on the Bio-Rad CFX96. Primer information is provided as follows.

Endo-Oct4-F: ATTCCCAACGAGAAGAGTATGA, EndoOct4-R: TCCCTTGCCTTGGCTCACAG;

$\beta$-actin-F: GAAATCGTGCGTGACATCAAAG, $\beta$-actin-R: TGTAGTTTCATGGATGCCACAG;

Zscan4-F: GAGATTCATGGAGAGTCTGACTGATGAGTG, Zscan4-R: GCTGTTGTTTCAAAAGCTTGATGACTTC;

Zscan4-endo-F2: CCTATGTAGCCGTCGCTTTC, Zscan4endo-R2: AAGTGGCAATCCACAAGCAT;

Trf2-F: GGTCTTCCAGCAGAAGATGC, Trf2-R: AAGCTGCCTTCAGAGTCCTG;

Pot 1b-F: TCCTCATACGAgGgaAgGTG, Pot1b-R: GATGCTGGGATCTGGAAAAA;

Rap1-F: CCGCTACCTCAAGCACCTAC, Rap1-R: CACTCCTCCTCAGGCAAGTC;

Trf1-F: GGACAGATTCGGATTCTCCA, Trf1-R: GCTGTCACGAGTACGACGAA;

Pot1a-F: AGCTTCACTCCTCAGGACCA, Pot1a-R: GGGTTCCATCCCATACCTTT;

Tpp1-F: TCGGATCCTAGCTCTCCTCA, Tpp1-R: AAAGTCCTGGGTGGTCACTG;

Tin2-F: GGAGTTTCTGCAGTCCTTGC, Tin2-R: TCTG-

\section{GACTCTGCTGGGAAGT}

\section{Teratoma formation and histological analysis}

iPS cells were suspended at $1 \times 10^{7}$ cells $/ \mathrm{ml}$ in MEF medium. Each nude mouse was subcutaneously injected in the dorsal flank with $100 \mu \mathrm{l}$ of cell suspension $\left(1 \times 10^{6}\right.$ cells $)$. Four to six weeks after the injection, teratomas were surgically dissected from the mice. Samples were fixed in PBS containing $4 \%$ formaldehyde and subsequently embedded in paraffin wax. Sections were stained with hematoxylin and eosin.

\section{Pulsed-field gel electrophoresis and terminal restriction fragment analysis}

TRF analysis was performed as described previously [41]. DNA was extracted from iPS cells and ES cells. A total of $15 \mu \mathrm{g}$ DNA was digested overnight with $\mathrm{MboI}$ at $37{ }^{\circ} \mathrm{C}$ and electrophoresed through $1 \%$ agarose gels in $1 \times \mathrm{TAE}$ at $14{ }^{\circ} \mathrm{C}$ using a CHEF Mapper ${ }^{\circledR}$ XA pulsed field electrophoresis system (Bio-Rad). Auto Algorithm was used to separate DNA samples with a size range from $7.5 \mathrm{~kb}$ to $100 \mathrm{~kb}$. The gel was blotted and probed with $(\text { TTAGGG })_{13}$ using DIG high prime DNA labeling and detection starter Kit II (Roche).

\section{Telomere Q-FISH}

Telomere FISH was performed using a telomere peptide nucleic acid (PNA; $0.5 \mu \mathrm{g} / \mathrm{ml}$ ) (Panagene, Korea) FISH Kit/FITC according to the manufacturer's instructions. Telomeres were denatured at $80{ }^{\circ} \mathrm{C}$ and hybridized with the telomere PNA probe. Chromosomes were stained with $0.5 \mu \mathrm{g} / \mathrm{ml} \mathrm{4',6-diamidino-2-phenylindole}$ (DAPI). Fluorescence from the chromosomes and telomeres was digitally imaged on a Zeiss microscope with fluorescein isothiocyanate (FITC)/DAPI filters using AxioCam and AxioVision software 4.6. Telomere length, presented in telomere fluorescence units, was integrated using the TFL-TELO program (kindly provided by P Lansdorp of Terry Fox's laboratory) and calibrated using standard fluorescence beads.

\section{Telomerase activity assay}

Cell lysates were prepared from $5 \times 10^{5}$ cells per sample. Samples that were incubated at $85{ }^{\circ} \mathrm{C}$ for $10 \mathrm{~min}$ served as a negative control. Telomerase activity was measured by the TRAP assay using a TRAPEZE Telomerase Detection Kit (Millipore) according to the manufacturer's instructions.

\section{Telomere CO-FISH}

Cell samples from different days (OSKM/OSKMZ) were cultured as previously described [41]. The medium was changed daily. 5'-Bromo-2'-deoxyuridine (BrdU) was added for $18 \mathrm{~h}$ to allow BrdU incorporation for one cell cycle. Demecolcine solution $(0.2 \mu \mathrm{g} / \mathrm{ml}$, Sigma $)$ was added for the final $5 \mathrm{~h}$. Metaphase spreads were prepared. Slides were stained with $0.5 \mu \mathrm{g} / \mathrm{ml}$ Hoechst 33258 (Sigma), washed in $2 \times \mathrm{SSC}$, and then exposed to longwave radiation (e.g., $365 \mathrm{~nm}$ ) in McIlvaine's buffer ( $\mathrm{pH} \mathrm{8.0)} \mathrm{for} 30 \mathrm{~min}$. The BrdU-substituted DNA was digested with $3 \mathrm{U} / \mu$ l Exonuclease III (Takara) for $10 \mathrm{~min}$ at room temperature. The leading strand telomeres were visualized with $\mathrm{Cy} 3$-conjugated DNA probes ( $\mathrm{Pa}$ nagene). Chromosomes were counterstained with $1 \mu \mathrm{g} / \mathrm{ml}$ DAPI (Sigma). Three independent experiments were carried out for each sample. 


\section{G-SCE assay}

Cell samples from different days (OSKM/OSKMZ) were cultured as previously described [41]. The medium was changed every day. BrdU was added for $18 \mathrm{~h}$ to allow BrdU incorporation for one cell cycle. Demecolcine solution $(0.2 \mu \mathrm{g} / \mathrm{ml}$, Sigma $)$ was added for the final $5 \mathrm{~h}$. Metaphase spreads were prepared. The slides were treated with $2 \mathrm{M} \mathrm{HCl}$ followed by $0.1 \mathrm{M} \mathrm{Na}_{2} \mathrm{~B}_{4} \mathrm{O}_{7}$. BSA ( $1 \%$, Sigma) was used to block nonspecific signal. The slides were incubated with anti-BrdU antibody (Sigma) at $4{ }^{\circ} \mathrm{C}$ overnight, followed by staining with the respective secondary antibodies conjugated to Alexa Fluor (Invitrogen). The cells were counterstained with DAPI (Sigma).

\section{Western blotting}

Cell samples from different days were extracted using cell lysis buffer containing PMSF (Beyotime). Insoluble material was pelleted by centrifugation at $13200 \mathrm{rpm}$ for $15 \mathrm{~min}$ at $4{ }^{\circ} \mathrm{C}$. Protein concentrations were determined using the Bradford assay (BioRad). The proteins were denatured, reduced, separated by SDSPAGE, and transferred onto nitrocellulose membranes (PROTRAN; Whatman, Schleicher \& Schuell). The membranes were blocked with $5 \%$ fat-free dry milk in TBS-Tween (TBST) for $60 \mathrm{~min}$, incubated with primary antibodies overnight at $4{ }^{\circ} \mathrm{C}$, washed three times with TBST for $10 \mathrm{~min}$, incubated with peroxidase-conjugated secondary antibody in TBST with 5\% fat-free dry milk for 90 min, and washed three times with TBST for $10 \mathrm{~min}$. Immunoreactive proteins were detected using SuperSignal West Dura HRP Detection Kits (Pierce). Images were taken using an infrared imaging system (ImageQuant LAS 4000).

\section{Immunofluorescence}

Cells were fixed with $4 \%$ paraformaldehyde, permeabilized with $0.1 \%$ Triton X-100, and blocked with $1 \%$ BSA (Sigma). The cells were then stained with primary antibodies against $\gamma-\mathrm{H} 2 \mathrm{ax}$ and Trf1, followed by staining with the respective secondary antibodies conjugated to Alexa Fluor (Invitrogen). The cells were counterstained with DAPI (Sigma).

\section{Diploid and tetraploid blastocyst injection and embryo transfer}

Diploid blastocysts were collected from the uterus of E3.5 superovulated ICR females mated with ICR males and maintained in KSOM medium with amino acids until iPS cell injection. For the blastocyst injection, cells were trypsinized, resuspended in mouse ES cell medium without LIF, and kept on ice. A flat tip microinjection pipette with an internal diameter of 15-18 $\mu \mathrm{m}$ was used for the injection. To generate mice by tetraploid embryo complementation, two-cell embryos were collected from the oviducts of ICR females and electrofused to produce one-cell tetraploid embryos that were then cultured in KSOM media. Approximately ten to fifteen iPS cells were injected into the tetraploid blastocyst cavity. The blastocysts were placed in KSOM with amino acids until embryo transfer. Ten to fifteen injected blastocysts were transferred to each uterine horn of 2.5-days-postcoitum pseudopregnant ICR females. Pregnant recipients with tetraploid embryos were subjected to caesarean section on day 18.5 of gestation.

\section{Genotyping}

The microsatellite markers used in SSLP were amplified using primer pair sequences obtained from the Mouse Genome Informatics website (The Jackson Laboratory, http://www.informatics. jax.org). DNA was extracted from the tail tips of the mice. Thirtyfive cycles of PCR amplification were performed, and the products were separated on a $3 \%$ agarose gel before visualization. Allele sizes were approximated based on the known allele sizes of the various inbred strains. The primers used to detect exogenous factors are shown below.

Zscan4f-Retro-F: CTTTCGCCAATCATCCACTT, Zscan4fRetro-R: CCTTGCAAAATGGCGTTACT Oct4-Retro-F: GCTTGGATACACGCCGC, Oct4-Retro-R: TTCATGTCCTGGGACTCCTC GAPDH-F: ACCACAGTCCATGCCATCAC, GAPDH-R: TCCACCACCCTGTTGCTGTA

\section{Acknowledgments}

We thank Drs S Dang and M Lei for critical and useful comments on this manuscript. We thank T Wei, Y Li and H Pang for technical assistance. This study was supported by the Ministry of Science and Technology of China (2009CB941101 to JL, 2009CB941000 to LL), the Chinese Academy of Sciences (XDA01010403 to JL), and the Shanghai Municipal Commission for Science and Technology (11ZR1443000 to XZ). JL gratefully acknowledges the support of SA-SIBS Scholarship Program.

\section{References}

1 Hochedlinger K, Plath K. Epigenetic reprogramming and induced pluripotency. Development 2009; 136:509-523.

2 Pera MF. Stem cells: The dark side of induced pluripotency. Nature 2011; 471:46-47.

3 Gonzalez F, Boue S, Izpisua Belmonte JC. Methods for making induced pluripotent stem cells: reprogramming à la carte. Nat Rev Genet 2011; 12:231-242.

4 Bar-Nur O, Russ HA, Efrat S, Benvenisty N. Epigenetic memory and preferential lineage-specific differentiation in induced pluripotent stem cells derived from human pancreatic islet beta cells. Cell Stem Cell 2011; 9:17-23.

5 Kim K, Doi A, Wen B, et al. Epigenetic memory in induced pluripotent stem cells. Nature 2010; 467:285-290.

6 Kim K, Zhao R, Doi A, et al. Donor cell type can influence the epigenome and differentiation potential of human induced pluripotent stem cells. Nat Biotechnol 2011; 29:1117-1119.

7 Polo JM, Liu S, Figueroa ME, et al. Cell type of origin influences the molecular and functional properties of mouse induced pluripotent stem cells. Nat Biotechnol 2010; 28:848855.

8 Stadtfeld M, Apostolou E, Akutsu H, et al. Aberrant silencing of imprinted genes on chromosome $12 \mathrm{qF} 1$ in mouse induced pluripotent stem cells. Nature 2010; 465:175-181.

9 Gore A, Li Z, Fung HL, et al. Somatic coding mutations in human induced pluripotent stem cells. Nature 2011; 471:6367.

10 Hussein SM, Batada NN, Vuoristo S, et al. Copy number variation and selection during reprogramming to pluripotency. Nature 2011; 471:58-62.

11 Laurent LC, Ulitsky I, Slavin I, et al. Dynamic changes in the copy number of pluripotency and cell proliferation genes in 
human ESCs and iPSCs during reprogramming and time in culture. Cell Stem Cell 2011; 8:106-118.

12 Lister R, Pelizzola M, Kida YS, et al. Hotspots of aberrant epigenomic reprogramming in human induced pluripotent stem cells. Nature 2011; 471:68-73.

13 Mayshar Y, Ben-David U, Lavon N, et al. Identification and classification of chromosomal aberrations in human induced pluripotent stem cells. Cell Stem Cell 2010; 7:521-531.

14 Kawamura T, Suzuki J, Wang YV, et al. Linking the p53 tumour suppressor pathway to somatic cell reprogramming. Nature 2009; 460:1140-1144.

15 Marion RM, Strati K, Li H, et al. A p53-mediated DNA damage response limits reprogramming to ensure iPS cell genomic integrity. Nature 2009; 460:1149-1153.

16 Hong H, Takahashi K, Ichisaka T, et al. Suppression of induced pluripotent stem cell generation by the p53-p21 pathway. Nature 2009; 460:1132-1135.

17 Sarig R, Rivlin N, Brosh R, et al. Mutant p53 facilitates somatic cell reprogramming and augments the malignant potential of reprogrammed cells. $J$ Exp Med 2010; 207:2127-2140.

18 Zhao XY, Li W, Lv Z, et al. iPS cells produce viable mice through tetraploid complementation. Nature 2009; 461:86-90.

19 Kang L, Wang J, Zhang Y, Kou Z, Gao S. iPS cells can support full-term development of tetraploid blastocyst-complemented embryos. Cell Stem Cell 2009; 5:135-138.

20 Brambrink T, Hochedlinger K, Bell G, Jaenisch R. ES cells derived from cloned and fertilized blastocysts are transcriptionally and functionally indistinguishable. Proc Natl Acad Sci USA 2006; 103:933-938.

21 Wakayama S, Jakt ML, Suzuki M, et al. Equivalency of nuclear transfer-derived embryonic stem cells to those derived from fertilized mouse blastocysts. Stem Cells 2006; 24:20232033.

22 Yang X, Smith SL, Tian XC, Lewin HA, Renard JP, Wakayama T. Nuclear reprogramming of cloned embryos and its implications for therapeutic cloning. Nat Genet 2007; 39:295302.

23 Falco G, Lee SL, Stanghellini I, Bassey UC, Hamatani T, Ko MS. Zscan4: a novel gene expressed exclusively in late 2-cell embryos and embryonic stem cells. Dev Bio 2007; 307:539550.

24 McKinnon PJ, Caldecott KW. DNA strand break repair and human genetic disease. Annu Rev Genomics Hum Genet 2007; 8:37-55.

25 Lukas J, Lukas C, Bartek J. More than just a focus: The chromatin response to DNA damage and its role in genome integrity maintenance. Nat Cell Biol 2011; 13:1161-1169.

26 Bonner WM, Redon CE, Dickey JS, et al. GammaH2AX and cancer. Nat Rev Cancer 2008; 8:957-967.

27 Hirata T, Amano T, Nakatake Y, et al. Zscan4 transiently reactivates early embryonic genes during the generation of induced pluripotent stem cells. Sci Rep 2012; 2:208.

28 Zalzman M, Falco G, Sharova LV, et al. Zscan4 regulates telomere elongation and genomic stability in ES cells. Nature 2010; 464:858-863.

29 de Lange T. How telomeres solve the end-protection problem. Science 2009; 326:948-952.

30 Takai H, Smogorzewska A, de Lange T. DNA damage foci at dysfunctional telomeres. Curr Biol 2003; 13:1549-1556.
31 Su TT. Cellular responses to DNA damage: one signal, multiple choices. Annu Rev Genet 2006; 40:187-208.

32 Ikbal M, Atasoy M, Pirim I, Aliagaoglu C, Karatay S, Erdem $\mathrm{T}$. The alteration of sister chromatid exchange frequencies in Behcet's disease with and without HLA-B51. J Eur Acad Dermatol Venereol 2006; 20:149-152.

33 Wang Y, Erdmann N, Giannone RJ, Wu J, Gomez M, Liu Y. An increase in telomere sister chromatid exchange in murine embryonic stem cells possessing critically shortened telomeres. Proc Natl Acad Sci USA 2005; 102:10256-10260.

34 Krizhanovsky V, Lowe SW. Stem cells: The promises and perils of p53. Nature 2009; 460:1085-1086.

35 Tapia N, Scholer HR. p53 connects tumorigenesis and reprogramming to pluripotency. J Exp Med 2010; 207:2045-2048.

36 Carter MG, Stagg CA, Falco G, et al. An in situ hybridizationbased screen for heterogeneously expressed genes in mouse ES cells. Gene Expr Patterns 2008; 8:181-198.

37 Hanna JH, Saha K, Jaenisch R. Pluripotency and cellular reprogramming: facts, hypotheses, unresolved issues. Cell 2010; 143:508-525.

38 Wang F, Yin Y, Ye X, et al. Molecular insights into the heterogeneity of telomere reprogramming in induced pluripotent stem cells. Cell Res 2012; 22:757-768.

39 De Boeck G, Forsyth RG, Praet M, Hogendoorn PC. Telomere-associated proteins: cross-talk between telomere maintenance and telomere-lengthening mechanisms. J Pathol 2009; 217:327-344.

40 Jain D, Cooper JP. Telomeric strategies: means to an end. Annu Rev Genet 2010; 44:243-269.

41 Blasco MA, Lee HW, Hande MP, et al. Telomere shortening and tumor formation by mouse cells lacking telomerase RNA. Cell 1997; 91:25-34.

42 Jiang J, Ding G, Lin J, et al. Different developmental potential of pluripotent stem cells generated by different reprogramming strategies. J Mol Cell Biol 2011; 3:197-199.

43 Li J, Mombaerts P. Nuclear transfer-mediated rescue of the nuclear genome of nonviable mouse cells frozen without cryoprotectant. Biol Reprod 2008; 79:588-593.

44 Eggan K, Akutsu H, Loring J, et al. Hybrid vigor, fetal overgrowth, and viability of mice derived by nuclear cloning and tetraploid embryo complementation. Proc Natl Acad Sci USA 2001; 98:6209-6214.

45 Stadtfeld M, Hochedlinger K. Induced pluripotency: history, mechanisms, and applications. Genes Dev 2010; 24:22392263.

46 Chen T, Yuan D, Wei B, et al. E-cadherin-mediated cell-cell contact is critical for induced pluripotent stem cell generation. Stem Cells 2010; 28:1315-1325.

47 Li W, Ding S. Small molecules that modulate embryonic stem cell fate and somatic cell reprogramming. Trends Pharmacol Sci 2010; 31:36-45.

48 Aasen T, Raya A, Barrero MJ, et al. Efficient and rapid generation of induced pluripotent stem cells from human keratinocytes. Nat Biotechnol 2008; 26:1276-1284.

49 Kim JB, Zaehres H, Wu G, et al. Pluripotent stem cells induced from adult neural stem cells by reprogramming with two factors. Nature 2008; 454:646-650.

50 Huangfu D, Maehr R, Guo W, et al. Induction of pluripotent stem cells by defined factors is greatly improved by small- 
molecule compounds. Nat Biotechnol 2008; 26:795-797.

51 Huangfu D, Osafune K, Maehr R, et al. Induction of pluripotent stem cells from primary human fibroblasts with only Oct4 and Sox2. Nat Biotechnol 2008; 26:1269-1275.

52 Shi Y, Do JT, Desponts C, Hahm HS, Scholer HR, Ding S. A combined chemical and genetic approach for the generation of induced pluripotent stem cells. Cell Stem Cell 2008; 2:525528.

53 Silva J, Barrandon O, Nichols J, Kawaguchi J, Theunissen TW, Smith A. Promotion of reprogramming to ground state pluripotency by signal inhibition. PLoS Biology 2008; 6:e253.

54 Marson A, Foreman R, Chevalier B, et al. Wnt signaling promotes reprogramming of somatic cells to pluripotency. Cell Stem Cell 2008; 3:132-135.

55 Darabi R, Arpke RW, Irion S, et al. Human ES- and iPSderived myogenic progenitors restore DYSTROPHIN and improve contractility upon transplantation in dystrophic mice. Cell Stem Cell 2012; 10:610-619.

56 Cheng L, Hansen NF, Zhao L, et al. Low incidence of DNA sequence variation in human induced pluripotent stem cells generated by nonintegrating plasmid expression. Cell Stem Cell 2012; 10:337-344.

57 Liu L, Bailey SM, Okuka M, et al. Telomere lengthening early in development. Nat Cell Biol 2007; 9:1436-1441.

58 Tanemura K, Ogura A, Cheong C, et al. Dynamic rearrangement of telomeres during spermatogenesis in mice. Dev Biol 2005; 281:196-207.

59 Marion RM, Strati K, Li H, et al. Telomeres acquire embryonic stem cell characteristics in induced pluripotent stem cells. Cell Stem Cell 2009; 4:141-154.

60 Huang J, Wang F, Okuka M, et al. Association of telomere length with authentic pluripotency of ES/iPS cells. Cell Res 2011; 21:779-792.

61 Siegl-Cachedenier I, Flores I, Klatt P, Blasco MA. Telomerase reverses epidermal hair follicle stem cell defects and loss of long-term survival associated with critically short telomeres. J Cell Biol 2007; 179:277-290.

62 Takahashi K, Yamanaka S. Induction of pluripotent stem cells from mouse embryonic and adult fibroblast cultures by defined factors. Cell 2006; 126:663-676.

(Supplementary information is linked to the online version of the paper on the Cell Research website.) 